\title{
Editorial
}

\section{Peer Relations in Early Childhood Contexts}

Numerous studies have documented how peer interactions shape children's social competencies and social lives later on. Some of these studies used samples of children in their preschool and middle childhood years (e.g., Hartup, 1996; Newcomb \& Bagwell, 1995; Newcomb, Bukowski, \& Pattee, 1993; Park, Lay, \& Ramsay, 1993), but most of them focused on adolescence (for an overview see Rubin, Bukowski, \& Parker, 2006). Only a few studies have dealt with examining the early onset of peer behaviors in infants and toddlers (Eckerman, Whatley, \& Kutz, 1976; Holmberg, 1980; Howes, 1987; Mueller \& Brenner, 1977; Mueller \& Vandell, 1979; Ross, 1982; Ross, Conant, Cleyne, \& Alevios, 1982). As long as the origins of peer behaviors remain deficiently understood, however, it is difficult to construct a coherent theoretical framework of peer interactions over the life span. Although Hazen and Brownell (1999) summarized more recent research on early peer relationships, it is rather difficult to draw conclusions on the developmental consequences of early peer interactions. The complexity in peer interactions, as well as many limitations in applying methods and measures on young, mostly non-verbally interacting children, may make it more difficult to reliably investigate early peer relations than in later stages in life (for comprehensive discussions see Ahnert, 2003; Friedlmeier, 2002; Hartup, 1999). Thus, we are especially proud to present some recent research aiming to reduce the lack of knowledge on peer interactions during the first three years of life.

The studies presented in this special issue are based on different theoretical perspectives and approaches which interpret peer interactions from contextual and cultural points of view, and use constructivist approaches as well as attachment theory in order to explain foundations and developments in early peer interactions. Whereas contextual approaches help us to compare infants and toddlers' interactions with peers, as well as with parents and other significant adults in everyday contexts, cultural perspectives remind us that the adult-made culture shapes those contexts perceptibly, for example, due to specific child-rearing practices. Moreover, the way in which toddlers form relations to their peers and how these early relations may appear, is central to constructivist approaches, which also speculate about the limited social skills and peer competencies available during the first three years of life. Since early relations might be grounded in the relationships that infants and toddlers first experience with their mothers, it is plausible to associate the emerging peer competence with infant-mother attachments. Furthermore, the various theoretical perspectives and approaches are differently reflected in the conceptual frameworks of the present studies, which were carried out in two different cultures of Western Europe (the Netherlands and Germany), as well as in farmer and forager cultures of Central Africa. In order to investigate meanings and further interactional features, as well as individual characteristics of peer interactions, all studies made use of strong methodological approaches to early peer relations. They included observational and quasi-experimental, cross-sectional 
and longitudinal designs to shed light onto the antecedents and consequences of early peer interactions.

Meanings in peer interactions. Peer interactions in early childhood were deficiently described if we used only structural, rather than semantic features of an interchange, during which interactional intentions of the interacting partner are inherent (Mueller, 1989). The shared meanings of peer interactions, however, are not directly approachable. Thus, Viernickel (2009) took great effort to analyze all possible meanings that toddlers may transmit, perceive and share together. Based on alterations of inductive and deductive strategies, she created a list of over 30 interactional themes that can be classified into three general topics, namely conflict, play, and socializing. Applying both the fine and rough structure of the coding manual allowed for the analysis of interindividual differences among toddlers with respect to gender and age. The studies by Ahnert (2009), as well as by Fouts and Lamb (2009) also applied defined coding manuals in order to identify interactional meanings among peers. Their studies examined the effect of specific child-rearing practices on interactional meanings, suggesting that peer interactions of the Western cultures differ tremendously from those of the two societies that Fouts and Lamb explored in Central Afri$\mathrm{ca}$. One of the striking differences here is the fact that possession conflicts, which are considered to drive identity development in humans in general, are indeed highly prevalent in early peer relations of the Western world, but they hardly occur among the forager peers, where cooperation was most important.

Child-and dyad-specific features in peer interactions. There is no doubt that the ability to interact with others in meaningful ways depends on social-cognitive skills. The extent to which young peers' actions are coordinated with each other depends on the individual's awareness of intentions involved in interactions (Brownell, Ramani, \& Zerwas, 2006; Carpenter, Nagell, \& Tomasello, 1998; Eckerman, Davis, \& Didow, 1989). When children begin to understand others' intentions, the quality of their own interactional behaviors may change. Evidence for such changes is provided in the quasi-experimental study by Hunnius, Bekkering, and Cillessen (2009) who demonstrated that the understanding of others' intentions clearly reduced interruptive behaviors among peers and improved the communication between them.

Regular and frequent experience with peers is needed for successful peer interactions as well as for developed social-cognitive competence. One goal of the study by Friedlmeier (2009) was to investigate the emergence of partner-dependent interaction behaviors among young children. Most interestingly, he found evidence that partnerdependent interactions started when children were about two years old. Hunnius and colleagues reported partner-dependent effects in peer interactions for antagonistic but not affiliative behaviors, suggesting that some forms of interaction behaviors may be more prone to be partner-dependent than others. Continuous opportunity to interact with same peers might also be important for the development of close relationships between peers (e.g. Gottman, 1983). Not surprisingly, in the study by Viernickel, friendship dyads revealed longer interaction processes than those of unspecified dyads. 
However, dyadic patterns should not be solely explained by a child's individual characteristics, but rather by the partners with whom the child is interacting (e.g., Ross et al., 1992). Friedlmeier was therefore interested as to whether and how young children internalize representations of their peer relations and maintain them in the form of interactional schemes. Adapting Kenny and LaVoie's (1984) Social Relation Model, Friedlmeier analyzed reciprocal processes in order to identify relationship schemes which reflect each child's ability to develop reciprocal relations towards different partners. In addition, the follow-up approach by Friedlmeier convincingly revealed that children's early relationship schemes were predictive of the social status in later peer groups such as those in kindergarten and elementary school.

Child-rearing practice and culture shaping peer interactions. The common view in the present debate about the impact of culture on individuals and groups is led by the assumption that cultures either prioritize individual choice over the group's needs or prioritize the group's needs over individual choice (e.g., Markus \& Kitayama, 1991). While studying German infants who were exposed to public child care groups, Ahnert (2010) contemplated about the extent to which social skills necessary for the group situation were prepared at home, individually by their parents. Parents, of course, are aware that they are limited in serving as a model for successful interactions with peers. Thus, most of them organize peer contacts around their neighborhoods, at play grounds and in informal play sessions if no child care center is around (Ladd \& Hart, 1992; Putallaz, Costazo, \& Smith, 1991). Ahnert's study discussed the question as to whether and to what extent interactional tendencies can and cannot be prepared at home for infants who are placed in child care centers daily. She explored infants' attachments to their mothers as well as to their primary care providers in the centers by applying assumptions and methods from attachment theory. Ahnert revealed that both infant-mother and infant-care provider attachments prepare, shape and regulate peer behaviors, suggesting specific individualized pathways to the peer relations in child care. In contrast, Fouts and Lamb demonstrated in their work on African farmers and forager societies, how toddlers enter the community life of this culture mostly in the company of juveniles, who do not only take the role of play partners, but that of caregivers as well. Clearly, these specific cultural settings enhance children's interdependence with peers from the beginning of social development (see also Mosier \& Rogoff, 2003; Rogoff, Mistry, Goncu, \& Mosier, 1993). As a consequence, the impact of infant-adult attachments on a child's peer competence might be less relevant, while the juveniles become more influential and open up a different pathway in the development of peer relations in those cultures. Fouts and Lamb's work should make us more sensitive towards cultural limitations of today's research on early peer behaviors.

The five contributions to this special issue addressed some central research issues on peer interactions and relations in infancy and toddlerhood, even though the results are culturally biased and need to be treated with caution if generalized across cultures. More cross-cultural research is necessary to gain closer insight into commonalities and differences in peer behaviors and related consequences for social development. 
However, this special issue has addressed the research topic of early peer relations, which seemed to be forgotten for a while even though it has always been central in the search for the developmental potentials in children's social development.

Wolfgang Friedlmeier and Lieselotte Ahnert

\section{References}

Ahnert, L. (2003). Die Bedeutung von Peers für die frühe Sozialentwicklung des Kindes [The importance of peers for early social development]. In H. Keller (Hrsg.). Handbuch der Kleinkindforschung [Handbook of research in early childhood]. 3. Auflage (pp. 493-528). Bern, Switzerland: Huber.

Ahnert, L. (2009). Early peer interaction in group care as related to infant-mother and infant-care provider attachments. European Journal of Developmental Science, 3, 408-420.

Brownell, C. A., Ramani, G. B., \& Zerwas, S. (2006). Becoming a social partner with peers: Cooperation and social understanding in one- and two-year olds. Child Development, 77, 803-821.

Carpenter, M., Nagell, K., \& Tomasello, M. (1998). Social cognition, joint attention, and communicative competence from 9 to 15 months of age. Monographs of the Society for Research in Child Development, 63 (4).

Eckerman, C. O., Whatley, J. L., \& Kutz, S. T. L. (1975). Growth of social play with peers during the second year of life. Developmental Psychology, 11, 42-49.

Eckerman, C. O., Davis, C. C., \& Didow, S. M. (1989). Toddlers' emerging ways of achieving social coordinations with a peer. Child Development, 60, 440-453.

Fouts, H. N., \& Lamb, M. E. (2009). Cultural and developmental variation in toddlers' interactions with other children in two small-scale societies in Central Africa. European Journal of Developmental Science, 3, 389-407.

Friedlmeier, W. (2002). Soziale Entwicklung in der Kindheit aus beziehungstheoretischer Perspektive: Inter- und intraindividuelle Prozesse für die Entwicklung sozialer Kompetenz. [Social development during childhood in relation-theoretical perspective: Inter- and intraindividual processes for the development of social competence]. Lengerich, Germany: Pabst Science Publisher.

Friedlmeier, W. (2009). Reciprocity and relationship schemes in early peer interactions. European Journal of Developmental Science, 3, 347-367.

Gottman, J. M. (1983). How children become friends. Monographs of the Society for Research in Child Development, 48 (3, Serial No. 201).

Hazen, N., \& Brownell, C. (1999). Early peer relationships [Special issue]. Early Education and Development, 10 (3).

Hartup, W. W. (1996). The company they keep: Friendships and their developmental significance. Child Development, 67, 1-13.

Hartup, W. W. (1999). Peer experience and its developmental significance. In M. Bennett (Ed.), Developmental psychology: Achievements and prospects (pp. 106-125). Ann Arbor, MI: Psychological Press.

Holmberg, M. (1980). The development of social interaction patterns from 12 to 42 months. Child Development, 51, 448-456.

Howes, C. (1987). Social competence with peers in young children: Developmental sequences. Developmental Review, 7, 252-272. 
Hunnius, S., Bekkering, H., \& Cillessen, A. H. N. (2009). The Association Between Intention Understanding and Peer Cooperation in Toddlers. European Journal of Developmental Science, 3, 368-388.

Kenny, D. A., \& La Voie, L. (1984). The Social Relation Model. In L. Berkowitz (Ed.), Advances in Experimental Social Psychology (pp. 141-182). Orlando, FL: Academic Press.

Ladd, G. W., \& Hart, C. H. (1992). Creating informal play opportunities: Are parents' and preschoolers' initiations related to children's competence with peers? Developmental Psychology, 28, 1179-1187.

Markus, H. R., \& Kitayama, S. (1991). Culture and the self: Implications for cognition, emotion, and motivation. Psychological Review, 98, 224-253.

Mosier, C. E., \& Rogoff, B. (2003). Privileged treatment of toddlers: Cultural aspects of individual choice and responsibility. Developmental Psychology, 39, 1047-1060.

Mueller, E. (1989). Toddlers' peer relations: Shared meaning and semantics. In W. Damon (Ed.), Child development today and tomorrow (pp. 313-331). San Francisco, CA: Jossey-Bass.

Mueller, E., \& Brenner, J. (1977). The origins of social skills and interaction among playgroup toddlers. Child Development, 48, 854-861.

Mueller, E., \& Vandell, D. (1979). Infant-infant interaction. In J. D. Osofsky (Ed.), Handbook of infant development (pp. 591-622). New York: Wiley \& Sons.

Newcomb, A. F., \& Bagwell, C. L. (1995). Children's friendship relations: A meta-analytic review. Psychological Bulletin, 117, 306-347.

Newcomb, A. F., Bukowski, W. M., \& Pattee, L. (1993). Children's peer relations: A meta-analytic review of popular, rejected, neglected, controversial, and average sociometric status. Psychological Bulletin, 113, 99-128.

Park, K. A., Lay, K.-L., \& Ramsay, L. (1993). Individual differences and developmental changes in preschoolers' friendships. Developmental Psychology, 29, 264-270.

Putallaz, M., Costanzo, P. R., \& Smith, R. B. (1991). Maternal recollections of childhood peer relationships: Implications for their children's social competence. Journal of Social and Personal Relationships, 8, 403-422.

Rogoff, B., Mistry, J., Goncu, A., \& Mosier, C. (1993). Guided participation in cultural activity by toddlers and caregivers. Monographs of the Society for Research in Child Development, 58 (8).

Ross, H. S. (1982). Toddler peer relations: Differentiation of games and conflicts. Canadian Journal of Behavioral Science, 14, 364-379.

Ross, H. S., Conant, C. L., Cheyne. J. A., \& Alevizos, E. (1982). Relationships and alliances in the social interaction of kibbutz toddlers. Social Development, 1, 1-17.

Rubin, K. H., Bukowski, W. M., \& Parker, J. G. (2006). Peer interactions, relationships, and groups. In W. Damon, R. M. Lerner, K. A. Renninger \& I. E. Sigel (Eds.), Handbook of child psychology; Volume 3: Social, emotional and personality development (pp. 571-645). Hoboken, NJ: Wiley.

Viernickel, S. (2009). Peer interactions in infant care: Formal attributes and sharing of meaning. European Journal of Developmental Science, 3, 326-346. 